\title{
The Application of Learning Plan Guidance in Chinese Reading Class
}

\author{
Tingli Pan \\ Chongqing Medical and Pharmaceutical College \\ Chongqing, China 404100
}

\author{
Lingfeng Xie* \\ Sichuan Institute of Education Sciences, Ziyang \\ Ziyang, China 641300 \\ *Corresponding Author
}

\begin{abstract}
This paper intends to reverse the "technical teaching" mode of Chinese teachers and explore a teaching mode of study-plan guidance learning that is based on the specific teaching situation and the characteristics of Chinese subject, which highlights the subject status of students' learning, and reflects the characteristics of Chinese subject. This paper attempts to construct the "three-point and one-side" classroom teaching structure and the "six-step" teaching process of Chinese reading course, which starts from the study of studyplan guidance, uses group cooperation as a fulcrum and ends with class type construction.
\end{abstract}

Keywords-Chinese reading; learning plan guidance; classroom teaching

\section{INTRODUCTION}

"Study plan guided learning" has been widely used in basic education and professional education. Due to the differences in education's regional characteristics, discipline characteristics, class type characteristics, individual differences of students and other aspects, as well as the imperfection and improper application of the theoretical research on learning case guidance, we often face a dilemma: On the one hand, if the teacher guides excessively, the student cannot realize independent study and the cooperation inquiry in a true sense; On the other hand, if the guidance of teachers is not enough, students' inquiry activities will be in disorder, thus they are unable to complete the learning task. As a result, the guiding effect of study plan is not good in practical application. Some teachers even give up study plan directly. As a result, starting from the Chinese reading class, we will explore how to apply "study plans' guidance" in the Chinese reading class.

So, what is the study plan guided method? Learning plan is a bridge that teachers use to help students master the content of textbooks, communicate learning and teaching. It is also an important medium for cultivating students' independent learning and their ability of building knowledge. It has the function of guiding "reading, listening, thinking and doing". In addition, learning plan not only has the function of guiding learning, but also has the function of "guiding teaching". The proposal of learning plan makes the cultivation of subjectivity and autonomy guaranteed by the teaching process structure, and also makes teachers' leading role more effective and tangible.
The teaching structure of "three points and one side" of learning plan guidance — the starting point of learning plan guidance, the fulcrum of group cooperation and the "three points and one side" of class type construction

The core concept of the class teaching research of Chinese literature study guidance relies on "guidance". That is, how can teachers guide students' learning, inspire their thinking and promote their growth? How can they promote their growth with the starting point of "learning plan guidance", the fulcrum of "group cooperation", and the final point of "class-based construction"? How can they focus on the classroom teaching structure that highlights students' independent and cooperative learning to help students to study independently, communicate cooperatively and discuss problems, so as to achieve the ultimate state of "teaching is for not to teach"?

Class structures

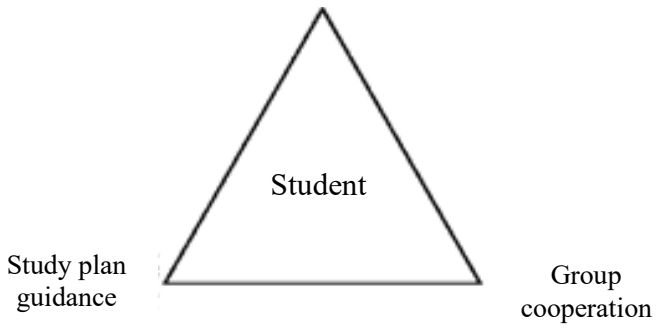

Fig. 1. "Three points and on side" Chinese literature stuan structure.

\section{CONSTRUCTION OF THE "SIX-STEP" TEACHING PROCESS OF CHINESE READING COURSE}

\section{A. Understanding of Reading Courses}

Reading class is the most common type of Chinese teaching. Its basic requirement is: the teacher guides the student to communicate with the text, with the author, and with them. While fully demonstrating the leading role of teachers, the teaching process should stimulate and mobilize students' learning enthusiasm, emphasize their main role in the process of reading, discussion, answering, writing and other ways, and cultivate students' listening, speaking, reading, writing ability and creative thinking. Take classical Chinese reading teaching 
as an example. In the traditional classical Chinese reading teaching, many teachers put a lot of time and energy on the classical Chinese knowledge. They ask students to technically recite after drilling the knowledge. As a result, students are passively under the suppression of the teacher's ideas, and are scattered in learning, unable to actively understand the author's thoughts and control the structure of the article, and unable to improve their reading ability.

\section{B. The Specific Implementation of the "Learning Plan Guidanceg" in the Reading Course}

1) To issue study plans and define the objectives: In this part, teachers are required to send the pre-written learning guidance plan to students two days in advance, so that students can clearly know the learning contents, learning objectives, key and difficult points, etc. Teachers can simply interpret the objectives to students: pointing out what to do, to what extent they shall do and giving students the appropriate guidance of learning methods. Students have to complete the rest of the study with goals. This can enable students to make a correct evaluation of the learning situation in a timely manner, check for omissions and make up for deficiencies, improve the structure of knowledge and ability, and improve the learning efficiency.

2) To prepare according to the study-plan and to feedback problems: After the learning objectives are defined, students are required to learn independently according to the guidance plan: they should independently read the content of teaching materials, consult materials, and complete the "learning tasks" of the guided learning plan. If there is any problem that cannot be solved in the process of learning alone, mark it with red pen, or write down other new problems in the learning notes column, so as to solve it later. This section can be left for students to complete after class. If students encounter more complex learning contents, they can also arrange one class for students to "learn alone".

After students finish the "independent learning" task within the specified time, the teacher can collect and review the study-plan, and then sort out the common problems of students according to their completion, so as to prepare for the later teaching. For the individual questions of students, teachers may give individual guidance or make notes on the study-plans, which not only examines students' preview, but also is the teacher's second preparation for the lesson. Of course, the task of "independent learning" can be checked by the teacher (random check), or by the group leader, or by students' mutual check etc. Then the class representative collects the questions and gives them to the teacher. This not only cultivates students' good habit of completing learning tasks on time, but also improves the benefits of relevant teaching activities.

3) Cooperation and communication, solving problems and dispelling doubts: For the First step, pair learning or group learning.

This session is arranged 10 minutes before the new class. During these 10 minutes, students are required to do "pair learning" according to their problems in self-learning. If "pair learning" cannot solve their problems, they should conduct "group learning" to complete the teaching content. "'Group learning" requires the team leader to complete the following three tasks:

First, actively share the self-study results, so that the members of the group can reach an agreement.

Second, initiatively put forward new questions and answer the questions of other team members. For problems that cannot be solved within the group, the group leader shall make a careful record, so as to propose to be solved by other group members or teachers during "class learning". Each member is required to speak during the panel discussion.

Third, the team leader shall assign specific display tasks and prepare for the group display: who raised questions of the group? Who are to show by the blackboard? How to present, by reading, writing, speaking, or acting?

The teacher should inspect the whole class whey they are doing "pair study" or "group study". They should participate in, collect students' questions and solve their problems timely. This link will effectively implement the code of "learning before teaching and problem-based teaching".

For the second step: studying in class.

This section is based on the students' "learning alone", "learning by pairs" and "group learning" and uses the middle 20 minutes of the class to carry out the class communication and learning activities. During this period, students need to be guided to actively answer the questions raised by other groups that cannot be solved in "pair learning" or "group learning".

Teachers, as instructors, should create democratic, harmonious, equal and free atmosphere, timely give instructions, guide students to question boldly, and to express their own views. When students do not explore enough, stay in a shallow level or deviate from the theme, teachers should timely ask, point out, inspire and guide them to seek solutions independently. The teacher should not interrupt the students or talk too much. Teachers should timely evaluate students' answers, in a word, to make them keep a best learning state, and keep the class an active learning state. In this link, the teacher can also teach important and difficult points that students meet during their communication and self-study. They should keep to the point, speak clearly with good reason. At the same time, we should take these problems as examples and elevate them from individual problems to general rules so that students can conclude the connections between old and new knowledge points under the guidance of teachers and build knowledge networks. In this way, the students' comprehensive ability of analysis can be cultivated, and the teaching effect can be understood.

In this link, attention should be paid to the following three aspects:

First, teachers should explain in groups. In front of the blackboard, group representatives analyze and explain the trace of thought and steps to solve problems, as well as the learning experience and inspirations; allow multiple forms of presentation, focus on the participation of students, and strive for the participation of students at different levels. 
Second, in view of the students' presentation, teachers and students make timely comments, or ask questions, and supplement in-depth inquiry.

Third, in the process of presentation, students should not only pay attention to the summary of knowledge, but also pay attention to students' language, demeanor, action, emotion, writing, etc., so as to give full play to the leading role of teachers.

4) Reaching the standard timely and optimizing the compensation: This link practices students to exercise knowledge learned through "consolidating key points", which can be placed in the last 10 minutes of class. The standard test is a timely compensation teaching for the feedback of students. Standard exercises should be limited in time and completed independently. Teachers patrol in the classroom, pay attention to the examination of students with learning difficulties, and collect information of students answering questions. After the completion of the exercise, teachers should timely check, give feedback and do correction. The basic requirements of feedback and correction are "timely feedback and timely correction; real feedback and accurate correction. Therefore, the exercises corresponding to each knowledge point should stick to the key, difficult, fallible, and confusing points, so as to consolidate the basic knowledge learned in this lesson.
Feedback correction is not only written practice, testing, but can also be questions, presentations, exercises and other forms. In order to enable students of different grades to experience success, stratified standardized tests can be adopted. The standard training is divided into A level and B level. Underachievers can only complete A level questions, excellent students need to complete both levels.

5) To extend and broaden students' horizon: This link may start from the knowledge points related to teaching materials to do an extension, broaden the students' knowledge vision, and enhance their study enthusiasm. In this link, teachers can flexibly master and timely control students' learning time.

6) Consolidation, summary, reflection and understanding: This link is completed after class. Students can summarize by themselves according to the situation of self-study, discussion and teachers' instructions. Summary can be to summarize the main points of knowledge, to talk about the effect of learning, to summarize the learning methods of this course, and to talk about the doubts after learning. In a word, the reflection after each lesson should be written into a text paragraph. Teachers should review the reflection and summary of students one by one to understand the learning state of students, so as to adjust the later teaching program.

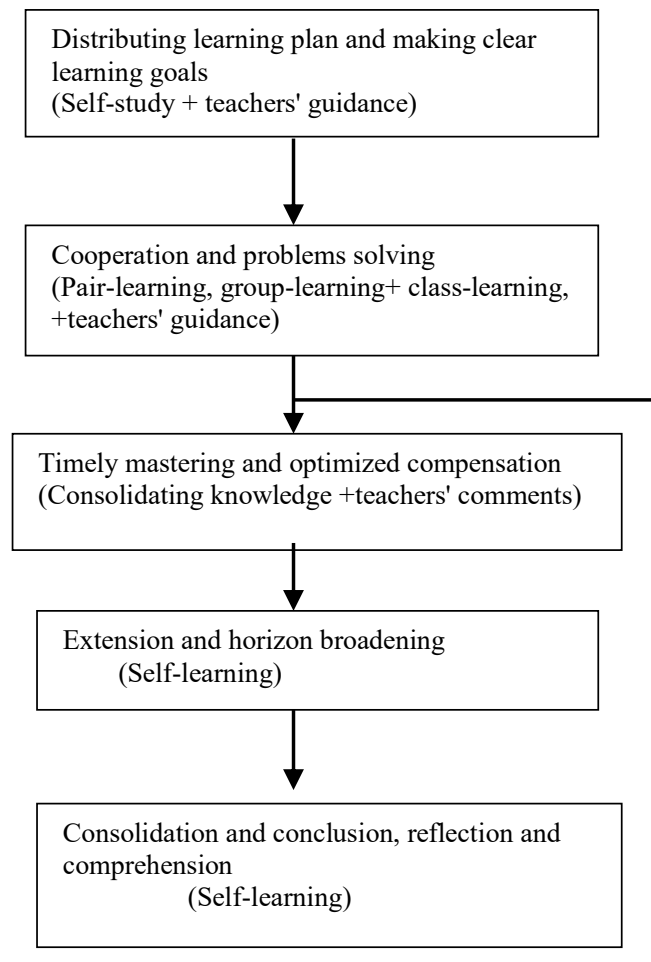

Fig. 2. The construction diagram of the reading course.

\section{CONCLUSION}

The learning plan guidance method changes the teacher's indoctrination teaching into the student's independent learning, enabling students to obtain the learning motivation. It turns students from "understanding what the teacher taught" to "understanding what they have learned"; from "being able to understand" to "being able to learn", which makes them grasp the effective learning methods. Also, it makes them change from "heteronomy" to "self-discipline". This will enable 
students to acquire self-confidence, self-esteem, and stimulate their internal learning potential.

But from another point of view, to promote the wide application of learning plan guidance method in Chinese teaching requires teachers to face all students in the teaching process. They should treat all students equally and create a stage for all students to express their talents so that every student can develop. In order to achieve the harmonious development of teaching and learning, teachers' guidance and students' learning should be carried out throughout the whole teaching process. They should never turn the entire classroom into a teacher's stage for their own speech or make students unstrained. Teachers should adopt a variety of teaching methods and advanced teaching methods. They should consolidate what students have learned in class and maximize classroom efficiency. At the same time, they should stimulate the interest of students and improve the effectiveness of teaching.

\section{REFERENCES}

[1] The Outline of the National Medium- and Long-Term Education Reform and Development Plan (2010-2020). The Standing Committee of the State Council, the Political Bureau of the CPC Central Committee and the Standing Committee of the National People's Congress Deliberated and Adopted it in 2010. (in Chinese)

[2] Outline of Basic Education Curriculum Reform (trial) issued by the Ministry of Education on June 8, 2001 (no.17 [2001] of basic education)

[3] Chinese Curriculum Standards for Ordinary Senior High Schools (experiment). Education Foundation of Ministry of Education [2003] no.6, issued on March 31, 2003. (in Chinese)

[4] Vincent $\mathrm{Yu}$. Learning before Teaching: Chinese Indigenous Pedagogy [J]. Courses. The teaching material. Sharia law. 2015 (2): 17-25. (in Chinese)

[5] Wang Aimin. Three Key Points in the Teaching Model of Guided Learning Plan [J] Teaching and Research World.2011 (2). (in Chinese)

[6] Zhao Jiachen. Zhang Cheng-Ju. Teaching Plan Design [M]. Beijing: China Light Industry Press, 2009. (in Chinese)

[7] Wang Tan. Cooperative Learning — Principles and Strategies [M]. Beijing: XueyuanPublishing House. 2001. (in Chinese)

[8] Lin Xiuyan. Wu Xinxin. Guo Minzheng. Green Dducation Middle School Chinese Class: Theory and Practice of Teaching Process [M]. Beijing: Beijing Normal University Press. 2014. (in Chinese)

[9] Ye Shengtao Chinese Education Analects [M]: Dducation Science Publishing House, 1980. (in Chinese)

[10] Sukhomlinski. Advice to Teachers [M]: Education Science Press, 1981.

[11] Zeng Xiangqin. On Chinese Teaching Ability [M]. Kaifeng: Henan University Press, 1987.7. (in Chinese)

[12] Shao Ruizhen. Psychology of Education [M]. Shanghai: Shanghai Education Press, 1988. (in Chinese)

[13] Dong Weigan. Reading Science [M]. Chongqing: Chongqing Publishing House, 1989. (in Chinese)

[14] Gu Huangchu, Li Xingbao. Chinese Language Education Anthology in The Early 20th Century [M]. Chengdu: Sichuan Education Publishing House, 1990. (in Chinese)

[15] Zeng Xiangqin. A New Theory of Reading [M]. Beijing: Chinese Language and Literature Press, 1999. (in Chinese)

[16] Wei Zhicheng. Teaching Theory of Modern Reading [M]. Guangxi: Guangxi Education Press, 2000.3. (in Chinese)

[17] Wang Shangwen. Research on Chinese Teaching in Middle Schools [M]. Beijing: Higher Education Press, 2002. (in Chinese)

[18] Liang Zhigang, Wei Xinlei. Walking into Muse - How to Read Literature [M]. Zhengzhou: Henan University Press, 2003.8. (in Chinese)
[19] Long Xietao. Literature Reading [M]. Beijing: Peking University Press, 2004. (in Chinese)

[20] Yan Guoli. Psychology of Reading Development [M]. Anhui: Anhui Dducation Press, 2004.8. (in Chinese)

[21] Yu Yingchao. Lecture 50 on the Art of Reading Teaching [M]. Xi 'an: Shanxi Normal University Press, 2005. (in Chinese)

[22] Yu Wensen, Zheng Jinzhou. Language Teaching and Learning of New Curriculum [M]. Fuzhou: Fujian Education Press, 2005. (in Chinese)

[23] Morey. Cognitive Research on Reading and Learning Psychology [M]. Beijing: Beijing Normal University Press, 2006.1. (in Chinese)

[24] Ni Wenjin. New Compilation of Chinese Curriculum and Teaching Theory [M]. Shanghai: East China Normal University Press, 2006.6. (in Chinese)

[25] Dong Beifei. Psychology of Chinese Education [M]. Shanghai: Shanghai Education Press, 2006.8. (in Chinese)

[26] Sun Shao-zhen. Literature Creation Theory [M]. Straits Literature and Art Publishing House, 2007.10. (in Chinese)

[27] Huang Houjiang. Huang Houjiang's speaking on Chinese [M]. Beijing: Chinese Publishing House, 2008. (in Chinese)

[28] Zhang Zhuoyu. Whether the Second Education Revolution is Possible -Humanistic Answer [M]. Beijing: Commercial Press. 2010. (in Chinese)

[29] Vincent Yu. "Instruction-independent learning" Teaching Reform Experiment: An Efficient Classroom Teaching Mode [M]. Fujian: Fujian Education Press. 2012. (in Chinese)

[30] Lin. Education is useless [M]. Beijing: Peking University press. 2014. (in Chinese)

[31] Li Xigui. Education [M] for individuals. Beijing: Education Science Press. 2014. (in Chinese)

[32] Li Xigui. School transformation [M]. Beijing: education science press. 2014. (in Chinese)

[33] Zhang Sibao. Operation manual of 24-word teaching mode [M]. Shanxi: Shanxi Publishing and Media Group. 2014. (in Chinese)

[34] Vincent Yu. Learning before teaching: Chinese Indigenous Pedagogy [J]. Courses. The Teaching Material. Sharia Law. 2015 (2): 17-25. (in Chinese)

[35] Reflections on Regional Implementation of New Curriculum. China education Journal.2007.5. Xinyang Normal University. Yang Guangqi, Wang Lijun, Guo Lihong. (in Chinese)

[36] Li Fengru. Research on "teaching plan" Chinese classroom teaching model [D] 2011. Excellent Master's Thesis of Yangzhou University. (in Chinese)

[37] Jia Rupeng, Fu Helun. Discussion on the teaching mode of "learning plan" [J] Education Scientific Research, 2004.7. (in Chinese)

[38] Some Thoughts on the Effectiveness of Learning Plan Teaching.[J] Teaching and Management, 2004.8. (in Chinese)

[39] Wang Aimin. Three key points in the teaching model of guided learning plan [J] World of Teaching and Research. 2011 (2). (in Chinese) 